\title{
PETER REDER
}

\section{Consultant responsibilities in child and adolescent mental health services teams: a systems dilemma}

\author{
AIMS AND METHODS \\ A number of relevant professional \\ bodies were invited to state their \\ views on the responsibilities of \\ consultant child psychiatrists within \\ multi-disciplinary teams in order to \\ ascertain whether there was any \\ consensus on the issue.
}

\author{
RESULTS \\ Little consensus or clarity emerged, \\ save for agreement on child psychia- \\ trists' expertise with medical matters. \\ Only medical organisations believed \\ in a notion of the consultant holding \\ ultimate responsibility, although \\ definition of this remained elusive.
}

\begin{abstract}
CLINICAL IMPLICATIONS
Consultants may need to seek clarity about their clinical and legal responsibilities from their employing Trust. However, there are many other dimensions to responsibility which have relevance for the training of child psychiatrists.
\end{abstract}

When anticipating becoming a consultant, the issue that exercises child psychiatry specialist registrars more than any other is the nature of their responsibilities within a multi-disciplinary team. The concern is by no means new and, as assumptions about the leadership role and status of doctors generally have been progressively challenged, it is not exclusive to child psychiatrists. However, it is felt particularly keenly within the speciality, which is regularly invited to contemplate its service organisation and priorities.

It is useful to consider the problem within a systemic frame of reference. The speciality cannot unilaterally present its own perspective without taking account of the views of all other professions within the multi-disciplinary team. Consultants enacting what they believe to be their appropriate role will inevitably receive feedback from other team members, whether facilitative or otherwise. At a wider level, teams operate as an organisation within the context of the NHS, which includes the expectations of commissioners and employers. Furthermore, many organisations now advise and comment upon NHS practices, and their opinions can carry a significant weight. Even if there are discrepancies between the positions adopted by the profession and others, it is essential to be aware of these differences and the likely areas of dissonance or conflict.

\section{A systemic exercise}

I decided to write to a number of relevant professional bodies to invite them to declare their opinions about the role of consultant child psychiatrists within multidisciplinary teams. I wanted to compare responses and identify similarities and differences, in the hope that this would clarify the optimal role for a consultant. Institutions were selected that:

(i) had a direct relevance for the psychiatric profession;

(ii) represented professions closely involved in child and adolescent mental health services;

(iii) represented service commissioners or managers;

(iv) advised on service delivery within the NHS.

I obtained permission to quote replies in any resulting publication.

\section{The responses}

\section{Medical / psychiatric institutions}

The Child and Adolescent Faculty of the Royal College of Psychiatrists was unable to reply at the time because it was still in the process of finalising its own statement about consultant responsibilities.

The British Medical Association (BMA) referred to its document Towards Tomorrow - The Future Role of the Consultant (1996), which concluded that consultants will continue to be recognised as team leaders, responsible for the allocation of duties within a team (but it was not clear who was being referred to as recognising this role). It also stated that, in multi-disciplinary teams, the team would be consultant-led. A more recent document, The Consultant Handbook (BMA, 2000) was also mentioned, particularly its statement that consultants are ultimately medically responsible in hospital units. This document further advised that consultants should delegate responsibility only when they are sure of the competence of the staff in question and that, if they were not medically qualified, such staff are accountable to a 
statutory regulatory body and a medical practitioner (such as a general practitioner) retains overall responsibility for the management of the patient.

The BMA's letter also made reference to the General Medical Council (GMC), stating that this body considers the consultant always takes ultimate responsibility. However, the GMC's actual reply contained only the brief reminder that it is the licensing body for the medical profession in the UK, adding that it was unable to offer advice on the responsibilities of a consultant psychiatrist, and suggested that the College should be approached.

The Medical Defence Union (MDU), on the other hand, based its response on the GMC's booklet Good Medical Practice (General Medical Council, 1998). This includes the guidance that, if medical practitioners lead a team, they must take responsibility for ensuring that the team's care is safe, effective and efficient, while remaining accountable for their own professional conduct and the care they provide. If they disagree with a team decision and believe that it would be harmful, they should first try persuasion, then inform someone who can take action, failing which they should take direct appropriate protective action themselves. Delegation is defined in the booklet as asking another health care worker to provide treatment on your behalf, while still remaining responsible for the overall management of the patient. Referral involves transferring some or all of the responsibility to another, when the same issues about statutory regulatory bodies and medical responsibility identified above pertain. The MDU's letter added that it would be advisable to make clear entries in the notes as to the responsibilities of each team member and to keep in good liaison with them. However, ultimately, as the responsible medical officer, you would be responsible for the overall management of your patient. In order to follow up this last point, I replied to the MDU asking for clarification of what constituted 'your patient' when working in a multi-disciplinary team. It suggested that the definition of a consultant's patients might be found in their contract.

\section{Institutions representing multi-disciplinary team members}

The British Psychological Society enclosed a copy of the section from its forthcoming document Responsibility and Accountability in Clinical Psychology headed 'Who Is Finally Responsible?' It argues that distinction must be made between medical responsibility as a professional issue, individual legal responsibility arising from the tort of negligence, and managerial responsibility for ensuring that procedures are implemented. In multi-disciplinary teams, responsibility for co-ordinating cases can be shared across disciplines but they may vary in different contexts and the psychologist must ensure that they are clearly defined.

The Association for Family Therapy offered informal views that the structure in a multi-disciplinary team should be clear, with medical responsibility remaining with the child psychiatrist, individual professionals being accountable through their profession for their specialist work, and all in the team being responsible to the team and to the trust. It suggested that the role of lead clinician implies the holding of responsibility and providing checks and balances about whole service provision. However, since clinical responsibility is more about the management of a case, co-ordination and quality assurance, this could be carried out by any discipline.

The Royal College of Nursing considered that it is important to distinguish between clinical governance responsibilities and team leadership. While the psychiatrist may need to position themself as the clinical leader because of their responsible medical officer role, they may not always be the most appropriate person to lead and manage the team or facilitate the work of others. Therefore, the team should agree its own operational policies.

The Association of Child Psychologists and Psychiatrists declared that it has no views on the issue. No reply was received from the Association of Child Psychotherapists.

\section{Institutions representing service commissioners or managers}

The position of the Department of Health, as ultimately overseeing the provision of all services, seemed particularly crucial. Its reply stated that the Department has not set out a view on the issue. Reference was made to its Handbook on Child and Adolescent Mental Health (Department of Health, 1995), which offered the general principal that teams should have clear systems of accountability and responsibility in place, although the means of achieving this was likely to differ between services. The level of leadership should be appropriate to the task and setting.

No response was received from the NHS Confederation or the British Association of Medical Managers.

\section{Institutions advising on service delivery}

Young Minds distinguished between the consultant psychiatrist's different potential roles as a clinician, as the senior consultant (thereby representing other consultants within the service), or in the formal managerial position as lead clinician. Clinically, it considered that the psychiatrist's core role is to apply medical and psychiatric expertise to the clinical requirements of the local population and, within the multi-disciplinary team, the consultant has a distinctive role by virtue of their medical training, diagnostic knowledge about mental disorders and illnesses, and therapeutic practices. Their responsibility includes overseeing and co-ordinating an appropriate delivery of service from the multi-disciplinary team.

The King's Fund felt unable to comment because it had not undertaken specific work in this area. No reply was received from the NHS Health Advisory Service.

\section{Inferences}

This was only a representative survey but it is evident that the issue has not been considered by all relevant 
(1)

special articles institutions, with some specifically believing that it is not within their province to comment. Even though a number of bodies have given careful thought to the question, they have also found it necessary to refer to statements available from others. The area of greatest consensus appears to be that doctors are responsible for medical matters, although the parameters and implications of this responsibility remain open to debate. The issues are obviously far from simple and many different factors need to be distinguished and defined, including: responsibility (such as clinical, medical, legal, managerial, for individual cases, for an overall service, for applying medical/psychiatric skills, and for applying wider clinical skills); RMO status; accountability; leadership; co-ordination; facilitation; the nature of inter-professional transactions on a case (especially 'your patient', referral, delegation, and working together in the same team); clinical governance; and quality assurance.

While we await guidance from the College, it is possible that this might not accord with assumptions held elsewhere. As the Department of Health indicates, the circumstances of individual teams are likely to differ, so that each service must address the issue for itself, apply the principles indicated above and aim for overt clarity about team relationships. If this is not possible, the emphasis made by some respondents on clinical governance and employment contracts could be a helpful way through a potential minefield. It may be that resolution lies within individual trusts and especially within their clinical governance structures and terms of reference.

\section{A personal view}

As this exercise revealed, it is common to focus on legal and professional issues when considering consultant responsibilities. However, there are other dimensions to responsibility which lie in the domains of personal, inter-personal and pragmatic functioning.

Personally, one has to assume a position of responsibility. This includes: acquiring, and then drawing upon, a wide and deep knowledge base (requiring appropriate training, ability to recognise and respond to rare or extreme examples of cases, and considerable practice experience); having the cognitive capacity to think hypothetically and to weigh up options; exercising an ability to problem solve, to make decisions, to 'get the job done', and to allow that 'the buck stops here'; and being prepared to admit when you do not know and to call upon the help of someone who may. Interpersonal aspects of taking responsibility within a team involve: skills at working with group processes; capacity to contain anxiety; demonstrations of leadership; and modelling the quality, ethical and other standards of the work group. Pragmatic considerations include: being personally available for consultation, to advise and to make decisions; ensuring that structures are in place to enable the work to be conducted effectively; and representing the work group at appropriate external forums. In other words, I would equate a role of special responsibility within a multi-disciplinary team with the functional leadership of that team.

Some may argue that such qualities are not the exclusive province of child psychiatrists and that they are embodied in other professions, especially psychology. While this may be partially true, I believe that doctors' professional development, starting with pre-registration house jobs, has set unique standards in all these aspects of responsibility. Part of the dilemma is that this uniqueness is no longer widely appreciated.

This, in turn, has relevance for the training of the speciality. In the past, child psychiatrists were trained in breadth and in depth, which allowed them to acquire the range of skills, detailed knowledge base and wide spectrum of experience expected of a responsible leader. They could assess and treat in a range of modalities and theorise using a number of frameworks. In many instances, these skills enabled them to earn the professional respect of other team members and the right to lead the service. However, we have progressively narrowed the range of knowledge and skills expected of a fully-trained child psychiatrist and some members of the profession even argue that our role is to remain focused on purely medical matters. In my opinion, such a narrow range of expertise would so undermine a consultant child psychiatrist's claim to hold ultimate responsibility within the service that they would lose the right to presume leadership of the team.

However, in the end, that may become the best resolution of a considerable systems dilemma.

\section{Declaration of interest}

None.

\section{References}

BRITISH MEDICAL ASSOCIATION CENTRAL CONSULTANTS AND SPECIALISTS COMMITTEE (2000) The Consultant Handbook, 4th Edition, London: BMA.

BRITISH PSYCHOLOGICAL SOCIETY (2001) Working inTeams: A Report by teh Division of Clinical Psychology. Leicester: The British Psychological Society.

DoH (1995) Handbook on Child and Adolescent Mental Health. West Midlands: NHS Executive.

GMC (1998) Good Medical Practice (booklet). London: GMC

MARRIOTT, C. (1996) Towards Tomorrow: The Future Role of the Consultant. London: Centra Consultants and Specialists Committee, BMA.

Peter Reder Consultant Child and Adolescent Psychiatrist, Child and Family Consultation Centre, 1 Wolverton Gardens, London W6 7DY, UK 